\title{
Anthropogenic Heat Flux Estimation from Space: Results of the first phase of the URBANFLUXES Project
}

\author{
Nektarios Chrysoulakis $^{*}$, , Mattia Marconcini ${ }^{\mathrm{b}}$, Jean-Philippe Gastellu-Etchegorry ${ }^{\mathrm{c}}$, C.S.B. \\ Grimmond $^{\mathrm{d}}$, Christian Feigenwinter ${ }^{\mathrm{e}}$, Fredrik Lindberg ${ }^{\mathrm{f}}$, Fabio Del Frate ${ }^{\mathrm{g}}$, Judith Klostermann ${ }^{\mathrm{h}}$, Zina \\ Mitraka $^{\mathrm{a}}$, Thomas Esch ${ }^{\mathrm{b}}$, Lucas Landier ${ }^{\mathrm{c}}$, Andy Gabey ${ }^{\mathrm{d}}$, Eberhard Parlow ${ }^{\mathrm{e}}$, Frans Olofson ${ }^{\mathrm{f}}$ \\ ${ }^{\mathrm{a}}$ Foundation for Research and Technology Hellas (FORTH), Heraklion, Greece \\ ${ }^{\mathrm{b}}$ German Aerospace Center (DLR), Wessling, Germany \\ cCentre d'Etude Spatiale de la Biosphère (CESBIO), Toulouse, France \\ ${ }^{\mathrm{d}}$ University of Reading, Reading, United Kingdom \\ eUniversity of Basel, Basel, Switzerland \\ ${ }^{\mathrm{f}}$ University of Goeteborgs, Goteborg, Sweden \\ ${ }^{\mathrm{g}} \mathrm{GEO}-\mathrm{K}$ s.r.l., Rome, Italy \\ ${ }^{\mathrm{h}}$ ALTERRA, Wageningen, The Netherlands
}

\begin{abstract}
H2020-Space project URBANFLUXES (URBan ANthrpogenic heat FLUX from Earth observation Satellites) investigates the potential of Copernicus Sentinels to retrieve anthropogenic heat flux, as a key component of the Urban Energy Budget (UEB). URBANFLUXES advances the current knowledge of the impacts of UEB fluxes on urban heat island and consequently on energy consumption in cities. This will lead to the development of tools and strategies to mitigate these effects, improving thermal comfort and energy efficiency. In URBANFLUXES, the anthropogenic heat flux is estimated as a residual of UEB. Therefore, the rest UEB components, namely, the net all-wave radiation, the net change in heat storage and the turbulent sensible and latent heat fluxes are independently estimated from Earth Observation (EO), whereas the advection term is included in the error of the anthropogenic heat flux estimation from the UEB closure. The project exploits Sentinels observations, which provide improved data quality, coverage and revisit times and increase the value of EO data for scientific work and future emerging applications. These observations can reveal novel scientific insights for the detection and monitoring of the spatial distribution of the urban energy budget fluxes in cities, thereby generating new EO opportunities. URBANFLUXES thus exploits the European capacity for space-borne observations to enable the development of operational services in the field of urban environmental monitoring and energy efficiency in cities.
\end{abstract}

Keywords: Copernicus Sentinels, Earth Observation, Urban Climate, Urban Energy Budget.

\section{INTRODUCTION}

The anthropogenic heat flux $\left(\mathrm{Q}_{\mathrm{F}}\right)$ is the heat flux resulting from vehicular emissions, space heating and cooling of buildings, industrial processing and the metabolic heat release by people. During the last years, significant advances have been made in the correct simulation of the physics of urban climate processes associated with higher computational capacity, improved spatial and spectral resolution of Earth Observation (EO) sensors and an increased ability to couple the schemes with atmospheric models. $\mathrm{Q}_{\mathrm{F}}$ is difficult to determine because of its strongly varying pattern and because it cannot be measured directly. It is therefore not surprising that many different approaches to estimate this term of the Urban Energy Budget (UEB) can be found in literature. Three general approaches have been recognized to estimate $\mathrm{Q}_{\mathrm{F}}{ }^{1}$ : the use of statistics on energy consumption; the closure of the energy budget and for the building sector, the building energy modelling approach:

*zedd2@iacm.forth.gr; phone 302810 391762; fax 302810 391761; http://rslab.gr

Remote Sensing Technologies and Applications in Urban Environments, edited by Thilo Erbertseder,

Thomas Esch, Nektarios Chrysoulakis, Proc. of SPIE Vol. 10008, 100080C

(C) 2016 SPIE · CCC code: 0277-786X/16/\$18 - doi: 10.1117/12.2239411 
- Inventories: A common approach is to estimate $\mathrm{Q}_{\mathrm{F}}$ based on inventories of existing socio-economic data. Most inventory-based estimations derive $\mathrm{Q}_{\mathrm{F}}$ from energy use data. $\mathrm{Q}_{\mathrm{F}}$ can be approximated on an hourly base utilizing different parameters for the three main contributors: traffic, stationary sources and metabolic release. The fraction of traffic as a function of type and amount of gasoline, the number of vehicles, their fuel efficiency and the travelled distance can be used. Recently, Iamarino et al. ${ }^{2}$ developed a novel method to estimate the spatial variability of $\mathrm{Q}_{\mathrm{F}}$ from buildings. It is a top-down approach based on high-resolution resident and workplace population data. They concluded that buildings, the major source of anthropogenic heat emissions, account for about $80 \%$ of the nearly 150 TWh of waste energy annually emitted across the city of London. As discussed by Sailor ${ }^{1}$ the inventory approaches all suffer from two main limitations: first, they can only resolve energy consumption at relatively coarse spatial and temporal scales and must use some technique to create estimates at finer scales; and second, they make the assumption that energy consumption is equivalent to anthropogenic sensible heat emissions.

- Residual of the UEB: A second approach to estimate $\mathrm{Q}_{\mathrm{F}}$ is to calculate it as the residual of the UEB. This is a more physical-based method, but all errors of the other terms are contained in the residual. For example energy balance closure has to be assumed although it is well known, that the turbulent heat fluxes are typically underestimated when the EC method is used. Another problem is that the storage term is usually calculated as the residual of the UEB. If daily or yearly totals of the energy balance equation are considered then $\Delta \mathrm{Q}_{\mathrm{S}}$ can be neglected and calculating $\mathrm{Q}_{\mathrm{F}}$ as the residual term is a reasonable approach ${ }^{3}$. The key limitations of this approach include a high level of uncertainty associated with some of the assumptions required to deduce anthropogenic heat as a residual in an energy budget. It is noted however that the EO potential to improve this approach is relatively unexploited since only few studies $^{4-6}$ have involved EO in $\mathrm{Q}_{\mathrm{F}}$ calculation.

- Estimates based on building energy models: Anthropogenic heating from the building sector is particularly complicated and it has been the subject of a number of focused studies. These studies generally involve explicit modelling of energy consumption within buildings and careful evaluation of heat emission. This type of models use GIS-based building prototypes to integrate building energy simulation results with an urban canopy meteorological model. Therefore, the building energy submodels explicitly account for building occupants, radiative transfer through windows, type of airconditioning heat exchanger (air-cooled vs evaporatively cooled), and performance of air-conditioning systems. The use of such a detailed building energy sub-model results in more realistic estimate of anthropogenic emissions ${ }^{1}$.

In non-urban settings, remotely sensed radiometric surface temperatures derived from thermal infrared imagery have been used extensively to model sensible heat fluxes, most typically over large homogenous areas and sometimes in conjunction with direct in-situ measurements. Over urban areas, thermal infrared imagery has been widely used to estimate surface UHI intensity, and to less extent to parameterize urban energy fluxes. Voogt and Grimmond ${ }^{7}$ successfully obtained urban sensible heat flux using a combination of airborne imagery, ground-based temperature measures and in-situ meteorological station data, whilst Offerle ${ }^{8}$ used four different aerodynamic methods and two flux models to derive urban sensible heat fluxes measures from ASTER and Landsat observations. Both these studies concluded that the flux modelling approach provided an acceptable means of estimating urban sensible heat fluxes, though some uncertainty remains on the accuracies that can be achieved. Chrysoulakis ${ }^{9}$ used ASTER multispectral imagery to estimate the net all-wave radiation balance, whereas $\mathrm{Xu}$ et al. ${ }^{6}$ explored the use of a new airborne hyperspectral remote sensing system, the Chinese Operative Modular Imaging Spectometer, to investigate the spatial distribution of sensible heat flux at various spatial scales in Shanghai. They concluded that if a high spatial resolution land cover map is not available for a particular study area where energy budget calculations need to be made, relatively consistent results may be gained using significantly lower spatial resolution data.

There is a need to develop uniform data for large samples of urban areas both within region and across regions. However, data for urban areas required in the analysis of energy fluxes are rarely collected and not in a consistent manner. One advantage of EO is the ability to capture consistent measurements across the universe of cities in order to understand something that might be relevant outside the jurisdiction of one particular urban area. Both urban planning and Earth system science communities need spatially disaggregated $\mathrm{Q}_{\mathrm{F}}$ data, at local (neighbourhood, or areas larger than the order of $100 \mathrm{~m} \mathrm{x} 100 \mathrm{~m}$ ) and city scales. Such information is practically impossible to derive by point in-situ fluxes measurements, while satellite remote sensing is a valuable tool for estimating UEB parameters exploiting Earth 
Observation EO data. While the estimation of $\mathrm{Q}_{\mathrm{F}}$ spatial patterns by current EO systems is a scientific challenge, the major challenge lies on the innovative exploitation of the Copernicus Sentinels synergistic observations to estimate the spatiotemporal patterns of $\mathrm{Q}_{\mathrm{F}}$ and all other UEB fluxes. URBANFLUXES (URBan ANthropogenic heat FLUX from Earth observation Satellites) was launched in 2015 to meet this challenge ${ }^{10}$.

URBANFLUXES is a joint effort of eight European Organizations aiming at introducing novel ideas on anthropogenic heat flux observation from space, and thus generating new EO opportunities to benefit climate change mitigation/adaptation and civil protection. Knowing the anthropogenic heat flux patterns in time and space can be an incentive for cooler urban design and support climate change mitigation and adaptation planning at local scale. Introducing spatio-temporal information on anthropogenic heat in urban planning can lead to a reduced winter and/or summer peak of heat emissions, a reduction in $\mathrm{CO}_{2}$ emissions, improved energy efficiency and better human comfort in the urban areas. The dependence of the URBANFLUXES method on EO data is one of its key advantages, giving the method the considerable leverage in transferability to any city. An easy and low-cost implementation to any city is expected. The research therefore will have the potential to support sustainable urban planning strategies, by taking into account the spatiotemporal distribution of $\mathrm{Q}_{\mathrm{F}}$ in cities. The long term operation of the Sentinels series guarantees the future supply of satellite observations, providing the means for the development and realization of the URBANFLUXES methodology.

An overview of the URBANFLUXES project is presented in this study, focusing on its objectives, methods and potential impact and presenting the results that came out during the first year of the project.

\section{FORMATTING OF MANUSCRIPT COMPONENTS}

The main goal of URBANFLUXES is to investigate the potential of EO to retrieve $\mathrm{Q}_{\mathrm{F}}$, supported by simple meteorological measurements. The main research question addresses whether $\mathrm{EO}$ is able to provide reliable estimates of $\mathrm{Q}_{\mathrm{F}}$ for the time of the satellite acquisition. URBANFLUXES answers this question by investigating the potential of EO to retrieve $\mathrm{Q}_{\mathrm{F}}$ spatial patterns, by developing a method capable of deriving $\mathrm{Q}_{\mathrm{F}}$ from current and future EO systems. URBANFLUXES aims to develop an EO-based methodology easily transferable to any urban area and capable of providing $\mathrm{Q}_{\mathrm{F}}$ benchmark data for different applications. URBANFLUXES is expected to increase the value of EO data for scientific analyses and future emerging applications (such as urban planning and local/regional level climate change mitigation/adaptation), by exploiting the improved data quality, coverage and revisit times of the Copernicus Sentinels data. To this end, the specific objectives of the project are:

- to improve the accuracy of the radiation balance spatial distribution calculation;

- to develop EO-based methods to estimate the flux of heat storage in the urban fabric, as well as the turbulent sensible and latent heat fluxes at local scale;

- to employ energy budget closure to estimate the anthropogenic heat flux patterns;

- to specify and analyse the uncertainties associated with the derived products;

- to evaluate the products by comparisons with $\mathrm{Q}_{\mathrm{F}}$ estimations by independent methods;

- to improve the understanding of the impact of $\mathrm{Q}_{\mathrm{F}}$ on urban climate; and to communicate this understanding to the urban planning community, which will in turn lead to a better understanding of what new knowledge is needed on the ground;

- to exploit Sentinels 2 and 3 synergistic observations to retrieve UEB fluxes at the local scale, with the frequency of the Sentinel 3 series acquisitions.

- to standardise the resulting products, and by organizing an effective dissemination mechanism, to enhance their use by urban planners and decision makers in cities, as well as by EO scientists, Earth system modellers and urban climatologists.

In URBANFLUXES, the UEB is considered in the context of a volume because of the three-dimensional nature of cities, as shown in Figure 1. Three different urban areas are selected in URBANFLUXES as case studies: a highly urbanized mega city (London); a typical central European medium size city, that requires a substantial amount of energy for heating (Basel); and a smaller, low latitude Mediterranean city that requires a substantial amount of energy for cooling 
(Heraklion). The project uses a Community of Practice (CoP) approach, which means that in the case studies, local stakeholders and scientists meet on a regular basis to learn from each other and to make clear what aspects are important for the future users of the URBANFLUXES products.

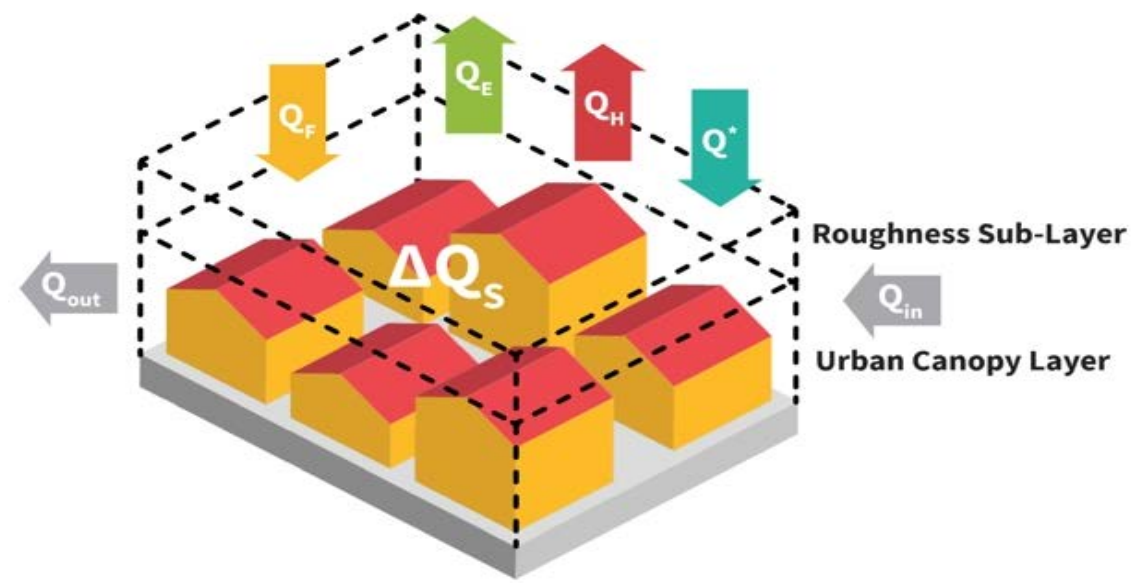

Figure 1. The UEB is defined: $\mathrm{Q}^{*}+\mathrm{Q}_{\mathrm{F}}=\mathrm{Q}_{\mathrm{H}}+\mathrm{Q}_{\mathrm{E}}+\Delta \mathrm{Q}_{\mathrm{S}}+\Delta \mathrm{Q}_{\mathrm{A}}+\mathrm{S}$, where $\mathrm{Q}_{\mathrm{F}}$ is the anthropogenic heat flux, $\mathrm{Q}^{*}$ is the net all-wave radiation flux, $\mathrm{Q}_{\mathrm{H}}$ is the turbulent sensible heat flux and $\mathrm{Q}_{\mathrm{E}}$ is the latent heat flux, $\Delta \mathrm{Q}_{\mathrm{S}}$ is the heat storage, $\Delta \mathrm{Q}_{\mathrm{A}}=$ $\mathrm{Q}_{\text {in }}-\mathrm{Q}_{\text {out }}$ and $\mathrm{S}$ represents all other sources and sinks, within the control volume.

The energy balance residual approach is used in URBANFLUXES. Although a rather straightforward method when the rest UEB components are known, its primary drawback is the accumulation of estimation errors of each energy budget flux in $\mathrm{Q}_{\mathrm{F}}$, in Figure 1; and the error of having neglected any unmeasured terms. Errors in the estimated flux terms include those stemming from normal observation inaccuracies plus the real spatial variability of the surface energy budget. In the framework of URBANFLUXES this spatial variability will be derived from satellite observations. Therefore, given small or unbiased $\Delta \mathrm{Q}_{\mathrm{A}}$ and $\mathrm{S}$ in Figure 1; and determining $\mathrm{Q}^{*}, \mathrm{Q}_{\mathrm{H}}, \mathrm{Q}_{\mathrm{E}}$ and $\Delta \mathrm{Q}_{\mathrm{S}}$ directly from EO data, with the support of standard meteorological observations, the expected value of the residual term would be a reliable estimate of $\mathrm{Q}_{\mathrm{F}}$, since, from a measurement perspective, it is impossible to remove anthropogenic contributions from the other terms shown in Figure 1. The $\mathrm{Q}_{\mathrm{F}}$ considered here captures only the effects of energy released within the system, which is not necessarily equivalent to energy consumption, as for example for the case of buildings, due to the heat transfer resistance between buildings and atmosphere and the thermal inertia of buildings. $\mathrm{Q}_{\mathrm{F}}$ is estimated by regressing $\left(Q_{H}+Q_{E}\right)$ versus $\left(Q^{*}-\Delta Q_{S}\right)$, defined for every pixel. Given that UEB closure is achieved, the regression will result in $\mathrm{Q}_{\mathrm{F}}$, estimating also the respective uncertainty. The following assumptions were made:

- all energy consumed in buildings is released into the environment after use;

- the term $\mathrm{S}$ is neglected;

- $\Delta \mathrm{Q}_{\mathrm{A}}$ is incorporated in the error $(\varepsilon)$ of $\mathrm{Q}_{\mathrm{F}}$ estimation from the UEB closure.

The URBANFLUXES approach is presented below. The cross cutting process of the CoP, which facilitates the continuous interaction with the users is clear. In the framework of the $\mathrm{CoP}$ the $\mathrm{Q}_{\mathrm{F}}$ related user requirements were captured and the demonstration of URBANFLUXES method and products will be performed. The duration of the project is three years and it is divided into two main phases: during the $1^{\text {st }}$ Phase an analysis method is being developed to estimate $Q_{F}$ spatial patterns using currently available satellite data; during the 2nd Phase the developed method will be adapted to Sentinels synergy to derive $\mathrm{Q}_{\mathrm{F}}$ spatiotemporal patterns. A network of simple meteorological stations has been deployed in all cities, whereas EC systems and scintillometrs are also be used. Satellite data are analyzed to map urban surface morphology and cover, whereas a new method is being developed to define UEB meaningful local zones. The Discrete Anisotropic Radiative Transfer (DART) model $^{11}$ is employed to improve the estimation of the net all-wave radiation balance, whereas the Element Surface Temperature Method (ESTM), as per Offerle et al. ${ }^{12}$, adjusted to satellite observations is used to improve the estimation the estimation of the net change in heat storage. Furthermore the estimation of the turbulent sensible and latent heat fluxes is based on the Aerodynamic Resistance Method (ARM) as per Kanda et al. ${ }^{13}$. Based on these outcomes, $Q_{\mathrm{F}}$ is estimated by regressing the sum of the turbulent heat fluxes versus the available energy. Finally, the whole approach will be adapted to Sentinels synergy to derive $\mathrm{Q}_{\mathrm{F}}$ spatiotemporal patterns. 


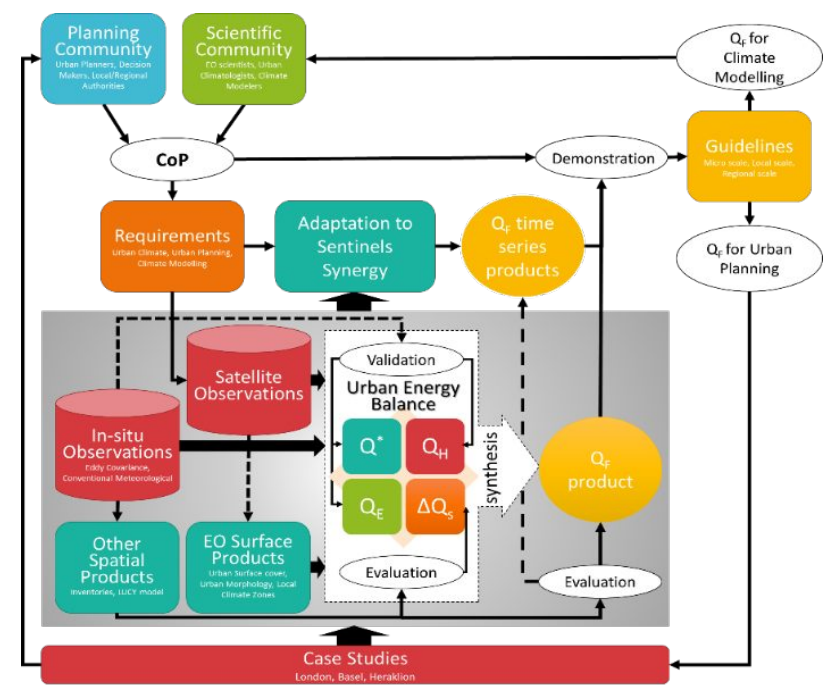

Figure 2. Flowchart of the URBANFLUXES methodology.

\section{RESULTS AND DISCUSSION}

During the first year of the project, a database containing satellite-derived urban surface morphology and cover characteristics, for the three case study cities, as well as a database containing the preliminary local zones for UEB mapping, have been developed; a database containing local scale multi-dimensional normalization functions of directional reflectance and brightness temperature, for any sun direction has been also developed, capable of being used in net all-wave radiation balance estimation. Furthermore, the ESTM has been adjusted to EO-derived surface morphology and characteristics and has been implemented for Basel and a test area in London. Finally, Wireless Sensors Networks (WSN) have been deployed in all case study cities, providing the appropriate in-situ air temperature and humidity measurements that are needed to estimate the respective gradients by the ARM, which has been implemented for Basel and for a test area in London. The estimated turbulent fluxes have been validated via direct comparisons versus the EC measurements.

A great wealth of spatial data related to the urban surface properties was produced. EO data from various sources, including the Copernicus Contributing Missions, was used to develop validated urban morphology and surface characteristics products for the three cities. Three product categories were developed: morphology, land cover and biophysical characteristics. The morphology products describe various aspects of the urban 3D structure and are derived from high resolution surface models. Surface information on building morphology, as well as vegetation eras available from Digital Surface Models (DSM). Most of the morphometric parameters were derived using the Urban Multi-scale Environmental Predictor ${ }^{14}$. The land cover products are obtained considering EO data at both high (HR) and very high (VHR) spatial resolutions. For the HR case, with a pixel size of $30 \mathrm{~m}$, the project has taken as reference input Landsat images. SPOT products $(2.5 \mathrm{~m})$ and Urban Atlas have been used for the VHR maps. The generation of land cover classification maps at two different spatial resolutions was motivated by at least a couple of reasons: first of all it is important to evaluate the impact of a coarser spatial resolution of the EO data on the estimation of $\mathrm{Q}_{\mathrm{F}}$; moreover, lower spatial resolutions can be more appropriate for detecting changed areas when the generation of updated products is required. For this task the URBANFLUXES is expected to exploit the advantages of the Sentinel missions. The biophysical products describe the dynamic land surface properties that are required in urban fluxes modelling. Properties such as surface reflectance, albedo, surface temperature and the seasonal vegetation changes are very important parameters of UEB. Various EO data sources were used for the development of such products and some of them are not in the desired spatial resolution. Thus, novel optimized downscaling techniques are developed from the URBANFLUXES team to enhance the spatial detail of biophysical products. Furthermore, URBANFLUXES started operation of WSN in the cities of Heraklion and Basel (similar network was also available for London). These WSN measure air temperature, relative humidity, infrared ground temperature, wind speed and wind direction. The measurements are available in real-time at URBANFLUXES website through a web-GIS interface. The resulted Sky View Factor (SVF) for central London, Land Cover map at VHR for Basel, as well as an example of air temperature measurements from the WSN of Heraklion are shown in Figure $3^{15}$. 


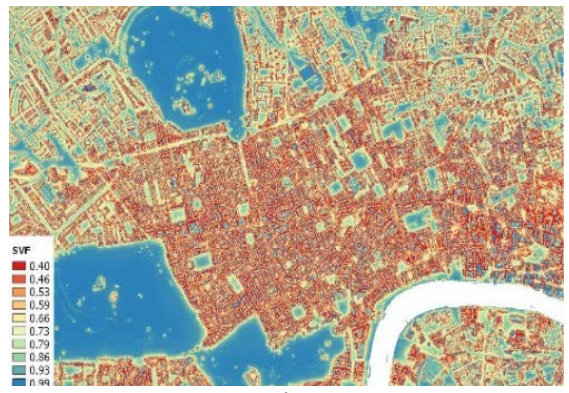

a)

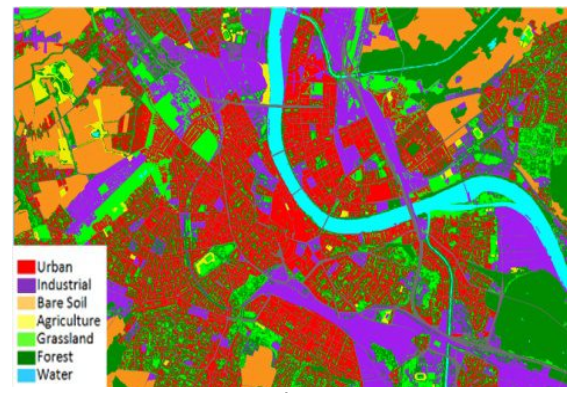

b)

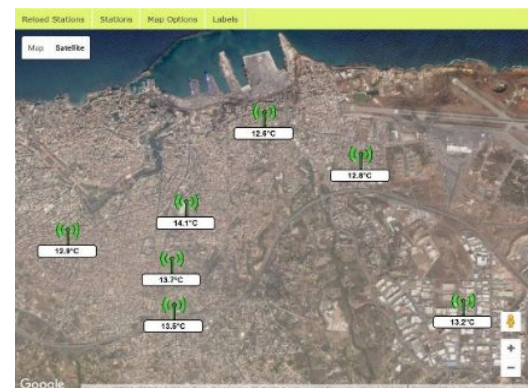

c)

Figure 3. a) SVF for central London; b) Land Cover map at VHR for Basel; c) Realtime air temperature measurements for Heraklion, as become available by the URBANFLXES web-site ${ }^{15}$.

The estimation of Q* needs the surface temperature and albedo. The surface temperature can be derived from satellite thermal infrared observations, however for the estimation of albedo, radiative transfer modelling is required to account for the urban surface anisotropy. In the framework of URBANFLUXES an original and operational methodology for deriving maps of urban albedo from satellite images was devised, without the need of in-situ measurements or information, although this type information could improve results. The DART model was calibrated with satellite observations to simulate the urban surface albedo at the time of satellite image acquisition and at the spatial resolution of the respective satellite image. DART can compute the albedo for any hour and date, using actual atmosphere data derived from in-situ or satellite acquisitions (e.g. ECMWF, Aeronet network, Sentinel-3). It is noted that the adjustment of DART to URBANFLUXES does not rely simply on a function of urban anisotropic reflectance. A major point of the two developed methodologies is take advantage of the urban databases (morphology and cover) described above. Figure 4 shows the estimated Q* for a Landsat scene (30 August, 2015 at 11:16 CET).

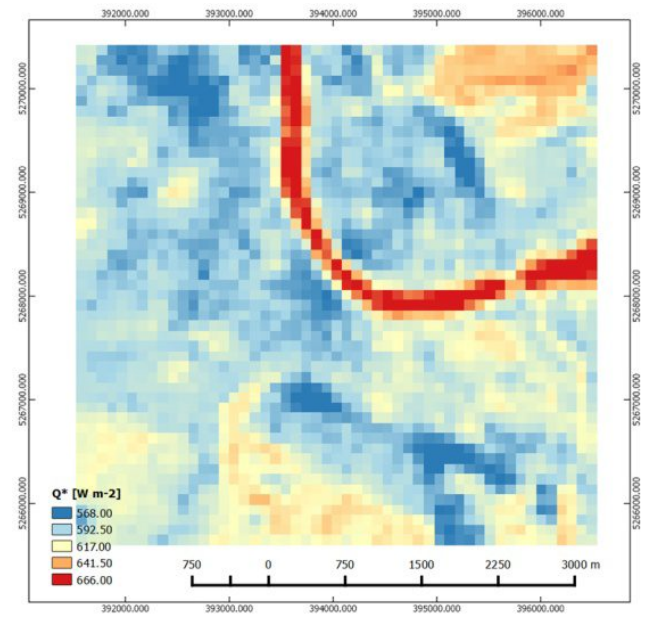

Figure 4. Net all-wave radiation for central Basel on 30 August, 2015 (11:16 CET), at $100 \mathrm{~m}$ x $100 \mathrm{~m}$ spatial resolution.

A sensitivity test was performed to prepare the implementation of the ESTM in URBANFLUXES case studies. From the initial sensitivity tests, the following results were drawn: there was low sensitivity to the internal air temperatures; the method of averaging component surface temperatures had a large influence; the results are sensitive to building dimensions used in the calculations; and the thermal responses of building material had a large effect. In this study, to consider the spatial variations of the storage heat flux a $5 \mathrm{~km}$ x $5 \mathrm{~km}$ area of central Basel was used. The spatial variation of $\Delta \mathrm{Q}_{\mathrm{s}}$ was calculated using a $100 \mathrm{~m} \times 100 \mathrm{~m}$ grid. Figure $5^{14}$ shows the estimated $\Delta \mathrm{Q}_{\mathrm{S}}$ for a Landsat scene (30 August, 2015 at 11:16 CET). In this example, the spatial pattern is affected by urban morphology and surface temperatures. Materials, indoor and outdoor air temperature were the same for the whole model domain. The highest $\Delta \mathrm{Q}_{\mathrm{S}}$ was found in the central parts of the city (the densest part of Basel, with the warmest surface temperatures at this time). Cooler areas, with lower building density, such as parks and open water, showed, as expected, lower $\Delta \mathrm{Q}_{\mathrm{s}}$. More detailed information on materials would probably accentuate the spatial differences of $\Delta \mathrm{Q}_{\mathrm{s}}$, given that dense urban areas tends to include materials, such as stone and concrete which have the ability to store more energy and hence increase $\Delta \mathrm{Q}_{\mathrm{s}}$. 


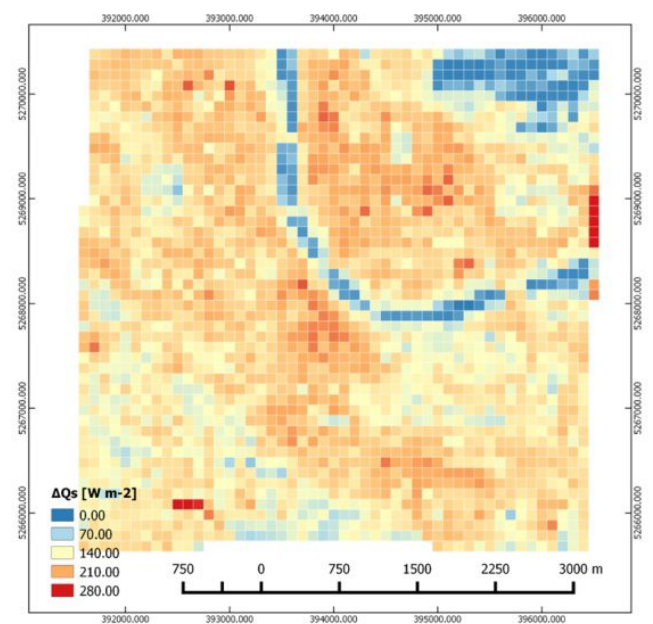

Figure 5. Storage heat flux calculations for central Basel on 30 August, 2015 (11:16 CET), at $100 \mathrm{~m} \times 100 \mathrm{~m}$ spatial resolution ${ }^{14}$.

The turbulent sensible $\left(\mathrm{Q}_{\mathrm{H}}\right)$ and latent $\left(\mathrm{Q}_{\mathrm{E}}\right)$ heat fluxes are strongly modified by the properties of the urban surface, i.e. 3D geometry, high roughness, impervious surfaces, complex source/sink distribution and injections of heat and water into the urban atmosphere by human activities (traffic, heating, waste management, etc.). In URBANFLUXES, the ARM was employed to estimate the turbulent heat fluxes by combining satellite and WSN observations. To determine the input parameters for the aerodynamic resistance, the approach of Xu et al. ${ }^{6}$ was modified to the satellite data. Both, roughness length (for heat and momentum) and displacement height were needed in this calculation. Roughness parameters were calculated using the real urban surfaces parameterization of Kanda et al. ${ }^{13}$. Stomatal resistance was calculated after Kato et al. ${ }^{16}$, using the simplified equation from Nishida et al. ${ }^{17}$. The roughness length for $\mathrm{Q}_{\mathrm{H}}$ and $\mathrm{Q}_{\mathrm{E}}$, as well as the minimum stomatal resistance for latent heat flux, interpolated based on the urban morphology and the urban surface characteristics, as they were derived from EO. WSN observations were used to support the turbulent fluxes estimation from EO data. Figure $6 \mathrm{a}^{18}$ shows the estimated $\mathrm{Q}_{\mathrm{H}}$ for a Landsat scene (30 August, 2015 at 11:16 CET). The spatial pattern is dominated by the fractions of transpiring and impervious surfaces in a $100 \mathrm{~m}$ x $100 \mathrm{~m}$ pixel. The highest sensible heat fluxes were found in the most densely built-up regions with high surface temperatures and missing vegetation. Finally, industrial areas showed high fluxes up to $300 \mathrm{~W} \mathrm{~m}^{-2}$ and more. The respective $\mathrm{Q}_{\mathrm{E}}$ is shown in Figure $6 \mathrm{~b}$.

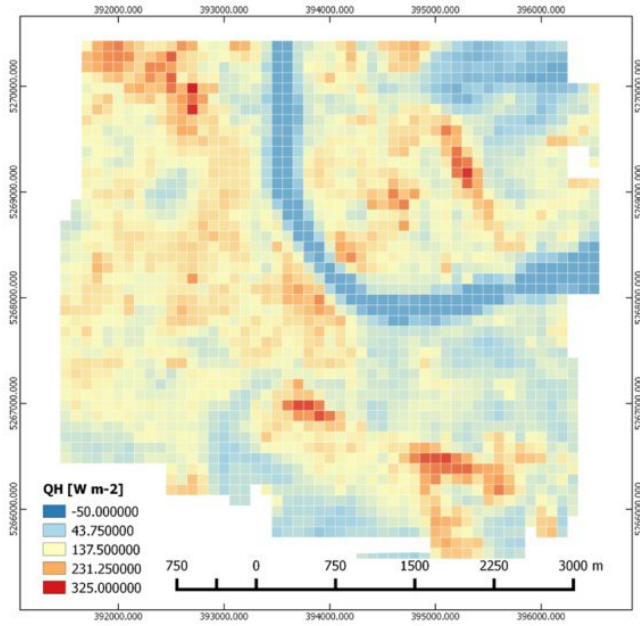

a)

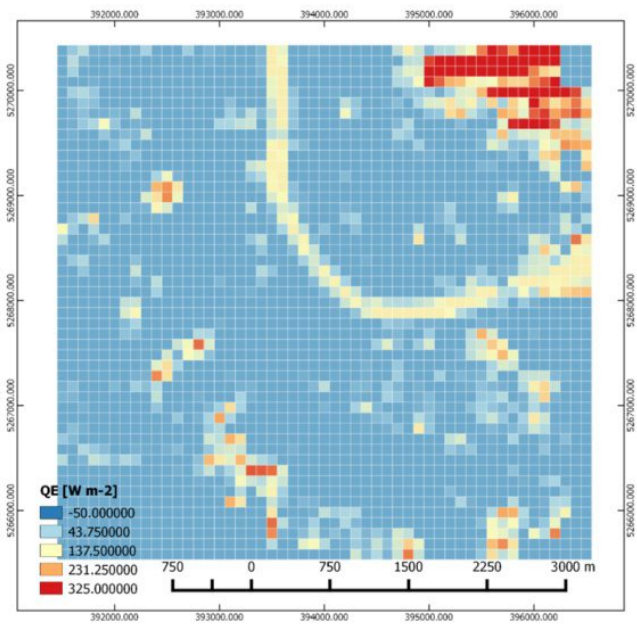

b)

Figure 6. Turbulent heat fluxes calculations for central Basel on 30 August, 2015 (11:16 CET) at $100 \mathrm{~m}$ x $100 \mathrm{~m}$ spatial resolution ${ }^{18}$ : a) sensible heat flux; and b) latent heat flux. 


\section{CONCLUSIONS}

Despite its local importance, the anthropogenic heat flux is omitted from climate models simulations. Observations of global temperature evolution indicate a pronounced warming over the last 150 years, with an increase in the occurrence of heat waves. The added value and benefit expected to emerge from URBANFLUXES is therefore related to quality of life, because it is expected to improve our understanding of the contribution of UEB to heat wave intensity and thus to allow insight into strategies for mitigation. UEB estimates are needed for all cities to be able to document the magnitude of the fluxes effects on urban climate so that the impact of the anthropogenic heat flux can be included in climate modelling. URBANFLUXES is therefore expected to advance the current knowledge of the impacts of UEB on urban heat island and hence on urban climate, and consequently on energy consumption in cities. This will lead to the development of tools and strategies to mitigate these effects, improving thermal comfort (social benefit) and energy efficiency (economic benefit). The long term operation of the Sentinels series guarantees the future supply of satellite observations, providing the means for the development and realization of the URBANFLUXES methodology.

URBANFLUXES is expected to support sustainable planning strategies relevant to climate change mitigation and adaptation in cities, because knowledge of UEB spatio-temporal patterns is important for urban planning (e.g. to reduce or prevent anthropogenic heat hot spots), health (e.g. to estimate the impact on thermal comfort) and future proofing (e.g. to plan and implement interventions towards anthropogenic heat reduction in these areas). Planning tools, such as Urban Climatic Maps and Climatope Maps, should be enriched with information on UEB patterns. Mapping provides visualization of assessments of these phenomena to help planners, developers and policy makers make better decisions on mitigation and adaptation.

\section{ACKNOWLEDGMENTS}

This project has received funding from the European Union's Horizon 2020 research and innovation programme under grant agreement No 637519.

\section{REFERENCES}

[1] Sailor, D. J., "A review of methods for estimating anthropogenic heat and moisture emissions in the urban environment,” Int. J. Climatol. 31(2), 189-199 (2011).

[2] Iamarino, M., Beevers, S.., Grimmond, C. S. B., "High-resolution (space, time) anthropogenic heat emissions: London 1970-2025,” Int. J. Climatol. 32(11), 1754-1767 (2012).

[3] Offerle, B., Grimmond, C. S. B.., Fortuniak, K., "Heat storage and anthropogenic heat flux in relation to the energy balance of a central European city centre,” Int. J. Climatol. 25(10), 1405-1419 (2005).

[4] Kato, S.., Yamaguchi, Y., "Analysis of urban heat-island effect using ASTER and ETM+ Data: Separation of anthropogenic heat discharge and natural heat radiation from sensible heat flux,” Remote Sens. Environ. 99(12), 44-54 (2005).

[5] Kato, S.., Yamaguchi, Y., "Estimation of storage heat flux in an urban area using ASTER data," Remote Sens. Environ. 110(1), 1-17 (2007).

[6] Xu, W., Wooster, M. J.., Grimmond, C. S. B., "Modelling of urban sensible heat flux at multiple spatial scales: A demonstration using airborne hyperspectral imagery of Shanghai and a temperature-emissivity separation approach,” Remote Sens. Environ. 112(9), 3493-3510 (2008).

[7] Voogt, J.., Grimmond, C., "Modeling surface sensible heat flux using surface radiative temperatures in a simple urban area,” J. Appl. Meteorol., 1679-1699 (2000).

[8] Offerle, B., "The energy balance of an urban area: Examining temporal and spatial variability through measurements, remote sensing and modeling,” Indiana University (2003).

[9] Chrysoulakis, N., "Estimation of the all-wave urban surface radiation balance by use of ASTER multispectral imagery and in situ spatial data,” J. Geophys. Res. 108(D18), 4582 (2003).

[10] Chrysoulakis, N., Esch, T., Gastellu-Etchegorry, J. P., Grimmond, C. S. B., Parlow, E., Lindberg, F., Frate, F. Del., Klostermann, J.., Mitraka, Z., “A novel approach for anthropogenic heat flux estimation from space,” 36th Int. Symp. Remote Sens. Environ. (ISRSE), 11-15 May, Berlin, Ger. (2015).

[11] Grau, E.., Gastellu-Etchegorry, J.-P., "Radiative transfer modeling in the Earth-Atmosphere system with 
DART model,” Remote Sens. Environ. 139, 149-170, Elsevier Inc. (2013).

[12] Offerle, B., Grimmond, C. S. B.., Fortuniak, K., "Heat storage and anthropogenic heat flux in relation to the energy balance of a central European city centre,” Int. J. Climatol. 25(10), 1405-1419 (2005).

[13] Kanda, M., Inagaki, A., Miyamoto, T., Gryschka, M.., Raasch, S., “A New Aerodynamic Parametrization for Real Urban Surfaces,” Boundary-Layer Meteorol. 148(2), 357-377 (2013).

[14] Lindberg, F., Olafson, F., Grimmond, C. S. B., "Spatial assessment of the heat storage flux ( $\Delta$ Qs). URBANFUXES Report D5.1” (2016).

[15] Del Frate, F., Latini, D., Heldens, W., Lindberg, F., Mitraka, Z., Grimmond, S., Gabey, A. M., Olofson, F., Feigenwinter, C., et al., "Urban surface morphology and land cober/use characteristics. URBANFUXES Report D3.1” (2016).

[16] Kato, S., Yamaguchi, Y., Liu, C.-C.., Sun, C.-Y., "Surface Heat Balance Analysis of Tainan City on March 6, 2001 Using ASTER and Formosat-2 Data,” Sensors 8(9), 6026-6044 (2008).

[17] Nishida, K., Nemani, R. R., Running, S. W.., Glassy, J. M., "An operational remote sensing algorithm of land surface evaporation,” J. Geophys. Res. Atmos. 108(D9), n/a - n/a (2003).

[18] Feigenwinter, C., Wicki, A., Parlow, E., Vogt, R., Heldens, W., Frate, F. del., Lindberg, F., Olofson, F., Mitraka, Z., et al., "Pixel based sensible (QH) and latent (QE) heat fluxes. URBANFUXES Report D6.1” (2016). 